\title{
Development of Dynamic Real-Time Navigation System
}

\author{
Shun FUJITA \\ Graduate School Student, \\ Graduate School of Information Systems, \\ University of Electro-Communications \\ Tokyo, Japan
}

\author{
Kayoko YAMAMOTO \\ Associate Professor, \\ Graduate School of Informatics and Engineering \\ University of Electro-Communications \\ Tokyo, Japan
}

\begin{abstract}
This study aimed to develop a system that considers dynamic real-time situations to provide effective support for tourist activities. The conclusions of this study are summarized in the following three points: (1) The system was developed by integrating Web-GIS, social media, recommendation systems and $A R$ terminals (smart glasses) into a single system, and operated in the center part of Yokohama City in Kanagawa Prefecture, Japan. It enabled the accumulation, sharing and recommendation of information and navigation to guide users to their goals both in normal conditions and in the event of disasters. (2) The web-based system was aimed at members of the general public over 18 years old and operated for seven weeks. The total number of users was 86 , and 170 items of information were contributed. A system using smart glasses operated for two days, and the total number of users was 34. (3) Evaluation results clarified that it was possible to support user behavior both in normal conditions and in the event of disasters, and to efficiently and safety conduct navigation using smart glasses. Operation premised on disaster conditions showed that users who accessed the system via mobile information terminals increased, and actively used functions requiring location information.
\end{abstract}

Keywords-Navigation System; Dynamic Real-Time; WebBased Geographical Information Systems (GIS); Social Media; Recommendation System; Augmented Reality (AR); Smart Glasses

\section{INTRODUCTION}

As many who visit sightseeing spots do not have a good sense of locality, they get to know the route to their destination by means of guidebooks using paper maps. However, carrying around maps is inconvenient, and because users must look up the route to their destination by constantly checking their current location on the map, this time consuming process may reduce their desire to sightsee. In addition, because many tourists do not have any knowledge about local disaster countermeasures including evacuation sites and support facility locations in the event of disasters, it will be extremely difficult for them to take necessary actions to evacuate. Also, in the event of disasters, although there are systems for supporting the evacuation of residents in the affected area, as these disaster countermeasure systems are not used in normal conditions, it will be difficult to suddenly use this system when disasters actually occur. Therefore, a system that is used in normal conditions in addition to one that supports the evacuation in the event of disasters by means of the same method used for normal conditions is necessary. From what is mentioned above, by means of the information system using the information of the situation around the user's location, in addition to appropriate support of sightseeing and evacuation, users can sightsee more efficiently and safely than before.

On the other hand, although navigation systems using mobile information terminals including smartphones are often used in recent years, using a smartphone while walking is called "wexting", and can be dangerous as it makes it hard for users to grasp their own surroundings. In contrast, with navigation using AR terminals (smart glasses) which is a type of wearable terminal, as information is displayed in front of the user's eyes without any special process, it is easy to grasp one's surroundings and can help users navigate safely. In addition, with the spread of social media in recent years, information related to sightseeing and disasters are being submitted and updated on social media in real time. Therefore, gathering real time information through social media, and reflecting that information both in sightseeing support in normal conditions and evacuation support in the event of disasters is necessary to realize a more efficient and safe sightseeing environment than before. Based on the circumstances mentioned above, the purpose of this study is to develop a navigation system that can actively alter routes, in order to gather high real time information concerning urban tourist spots as well as support sightseeing in normal conditions as well as evacuation in the event of disasters.

\section{RELATED WORK}

This study is related to (1) the study concerning the sightseeing support system, (2) the study concerning the Point of Interest (POI) recommendation system, and (3) the study concerning social media GIS. To list the representative preceding studies in recent times of the three groups mentioned above, regarding (1), Kurata (2012) [1] developed an interactive trip planning support system using genetic algorithm which can be used on the web. Sasaki et al. (2013) [2] developed a system that collects information regarding regional resources, and supports the tours of each user. In addition, Fujitsuka et al. (2014) [3] developed an outing plan recommendation system using the pattern mining method that lists and extracts the time series activities of users visiting sightseeing spots. Ueda et al. (2015) [4] generated post-activity information from the user's activities while sightseeing, and developed a sightseeing support system that shares the information as pre-activity information for other users. 
Regarding (2), Noguera et al. (2012) [5] developed a POI recommendation system by means of the methods of both collaborative recommendation and knowledge-based recommendation on $3 \mathrm{D}$ maps, using mobile terminals with the location information as the basis. In addition, studies related to POI recommendations concerning LBSN (Location-Based Social Networks) are also included in this field. Meo et al. (2011) [6] proposed and evaluated the preference and social and geographical effect of users concerning LBSN, Yuan et al. (2013) [7] proposed and evaluated the time and space information using the check in data concerning LBSN, and Chen et al. (2016) [8] proposed and evaluated the POI recommendation method which considers the interrelationship between users concerning LBSN.

Regarding (3), Yanagisawa et al. (2011) [9] in addition to Nakahara et al. (2012) [10] developed an information sharing GIS with the purpose of accumulating and sharing information regarding the local community using Web-GIS, SNS and Wiki. Yamada et al. (2013) [11] and Okuma et al. (2013) [12] developed a social media GIS which reinforced the functions of social media included in the information sharing GIS as mentioned above. By using the systems of these preceding studies as a base, Murakoshi et al. (2014) [13] in addition to Yamamoto et al. (2015) [14] developed social media GIS for the utilization support of disaster information assuming it will be used continuously from normal conditions to when disasters occur. Additionally, with the social media GIS as a base, Ikeda et al. (2014) [15] developed social recommendation GIS which recommends sightseeing spots according to the preferences of each user by integrating the recommendation system with the social media GIS mentioned above.

Among the preceding studies in related fields as listed above, (1)(2)(3) support the tour planning and accumulating, sharing and recommending of sightseeing spot information for sightseeing activity support in normal conditions, and (3) performs the accumulating and sharing of disaster information for evacuation support in the event of disasters. However, these preceding studies do not go further than offering information to users by means of accumulating, sharing and recommending information, which is realistically not enough to support the activities of users. Additionally, they do not support the users' activities for both sightseeing in normal conditions and evacuation in the event of disasters. In contrast to these preceding studies in related fields, this study shows individuality in developing a system, which supports sightseeing in normal conditions and evacuation in the event of disasters by means of navigation, by integrating SNS, Twitter, Web-GIS, recommendation systems and smart glasses.

\section{OUTLINE AND METHOD OF THIS STUDY}

This study will follow the outline and methods as shown below. First, the navigation system which specializes in the purpose of this study will be designed (Section III) and developed (Section IV) originally. Next, assuming users are over the age of 18 , operation tests and operation (Section V) of the navigation system in addition to the evaluation and extraction of solutions (Section VI) will be conducted. Also, assuming each user will be using this system for approximately 1 month, operation will start after conducting operation test and evaluations. In addition, Web questionnaire surveys to users and access analysis using the log data during the operation will be conducted, and with the obtained results, the solution extraction for this system will be conducted by evaluating the system.

The central part of Yokohama city in Kanagawa Prefecture, Japan has been selected as the region of operation. The reason for this is that (1) there is a variety of sightseeing spots, as it is an urban tourist destination, which enable recommendations of sightseeing spots to be made according to each user's preferences, and (2) because tourists and sightseeing spots are concentrated in a small area, a lot of information concerning sightseeing spots are transmitted and the obtainment of real time information is made possible.

\section{SYSTEM DESIGN}

\section{A. System configuration}

The system of this study is developed by means of SNS, Twitter, Web-GIS, recommendation system and smart glasses, as shown in Fig. 1. With the support of both sightseeing and evacuation as the purpose of this study, the activities of users are supported by means of the navigation that can actively change routes. Concerning navigation, in the case of sightseeing, information of the route to a single sightseeing spot from the current location of the user as well as routes for touring a group of sightseeing spots are provided. Additionally, in the case of evacuation, information including the closest evacuation sight from the current location of the user and routes to the support facility in the event of disasters are provided. Also, on Twitter and SNS, which is originally developed, information concerning sightseeing spots including that of various events as well as disaster information of nearby areas will be obtained in real time, and the navigation route will change according to the information provided if necessary. By means of such a navigation system that focuses on obtaining real time information, the efficient support of both sightseeing and evacuation is realized.

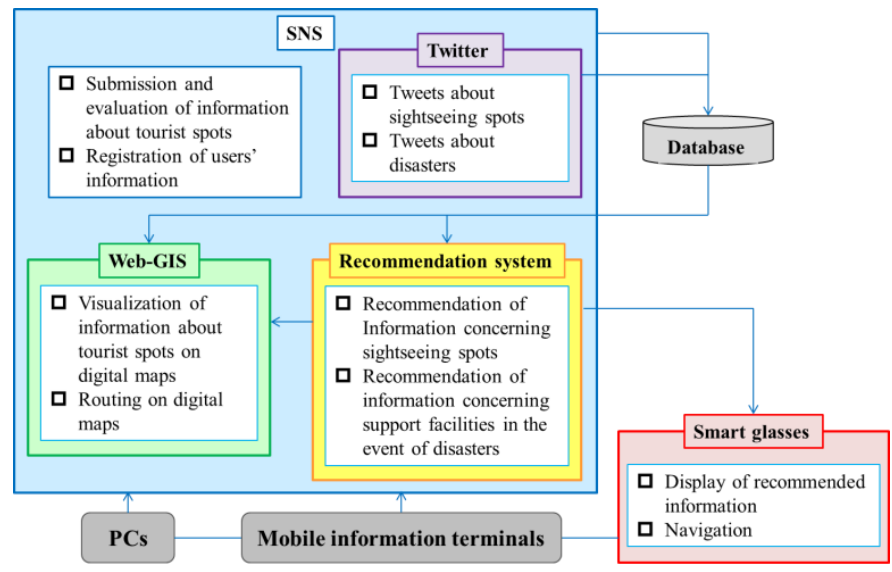

Fig. 1. System design of dynamic real-time navigation system

\section{B. System usability}

The usability of this system can be described in detail as shown below by means of the design mentioned in the previous section. 


\section{(1) Relaxation of time restrictions}

Concerning PCs and mobile information terminals, the system gets a time restriction in providing information to users, as it provides information after receiving requests from users,. By using smart glasses, the information provided by the system will constantly be displayed in front of the users. Therefore, because information is provided regardless of whether or not users make requests, the system will not have to rely on time restrictions. Consequently, it will be possible for information to be provided to users without losing its real time quality.

\section{(2) Active and real time information}

Without being limited to information accumulated in the past, by immediately reflecting real time information, which is obtained through originally developed SNS and Twitter, in recommendations, information can be provided to users efficiently. Based on such real time information, active information appropriate to each user's location can be provided.

\section{(3) Load reduction of information obtainment}

In the case of information overload along with the system's long-term operation, this system can provide information appropriate for each user by means of the recommendation system. In addition, as information is provided whenever necessary while using the smart glasses, opportunities for users to use information terminals in order to request information will be reduced. Therefore, the load of users when obtaining information can be reduced, and sightseeing in normal conditions and evacuation in the event of disasters can be focused on.

\section{Target terminals}

This system is set with the assumption that it will be used from PCs, mobile information terminals and smart glasses. Because PCs are assumed to be used indoors, the submitting, viewing and recommending function of sightseeing spot information, registration function of activity history, support function for planning sightseeing trips and navigation functions, which are described in detail in Section IV, will all be available. Assuming mobile information terminals will be used indoors and outdoors, the submitting and viewing function of sightseeing spot information as well as the navigation function will be the main functions. However, because using mobile devices while walking can be dangerous, assuming the use of the smart glasses which displays information in front of the user as well, safe navigation will also be realized.

\section{System operating environment}

This system uses the web server, database server and the GIS server for operation. The web server and database server were prepared using the Heroku. Heroku is the PaaS supplied by the Salesforce company, and it provides a platform which operates web applications. In addition, GIS servers use the ArcGIS Online of the ESRI. As the main language, the web applications developed by this system are implemented by Python and JavaScript, while the smart glasses' application is implemented by Java.

\section{E. System structure}

\section{1) $S N S$}

In this study, an original SNS, which can be integrated with Twitter, Web-GIS, the recommendation system and smart glasses, will be designed. As the purpose of the designed SNS will not only be communication between users but also the gathering of sightseeing spot information, which will serve as the base information for preference information of users as well as recommendations, functions that promote friend registration and community communication will not be implemented. The main functions of the designed SNS will be the registration of user information and the submitting, viewing and recommending of information. The information made public through profiles will use nicknames instead of real names, and information that may identify an individual, such as gender or age, will not be made public. The comment function and tag function were designed as a method of communication. Comments that are submitted by means of the comment function will also be used as real time information. In addition, tags that have been added to sightseeing spots by means of the tag function will be treated as features of the sightseeing spots, and will be used by the recommendation function of sightseeing spots with the preference information of users as the base.

\section{2) Web-GIS}

As this study assumed that the system users will be an unspecified large number from both inside and outside the region of operation, it is better if the system can be used by means of a web browser instead of having users install a special software. Additionally, it is necessary to conduct route searches as well as information visualization on digital maps. Therefore, the Web-GIS, which was developed using the ArcGIS API for JavaScript of the ESRI, will be used. Also, for route searches, the ArcGIS Online Directions and Routing Services will be used. Although Google Maps was the most used in preceding studies of related fields listed in Section II, as searches of routes that do not go through a specific location, which is necessary for evacuation support in the event of disasters, are impossible concerning this system, ArcGIS API for JavaScript is used in this study.

The process up to the display of routes regarding Web-GIS, which used the ArcGIS API for JavaScript and ArcGIS Online Directions and Routing Services as mentioned above, is as shown in Fig. 2. First, the request for a route search as well as search criteria will be sent from ArcGIS for JavaScript API to the ArcGIS Online Directions and Routing Services. Next, after receiving route search results from the ArcGIS Online Directions and Routing Services, the route will be displayed on the Web-GIS developed by means of ArcGIS for JavaScript API.

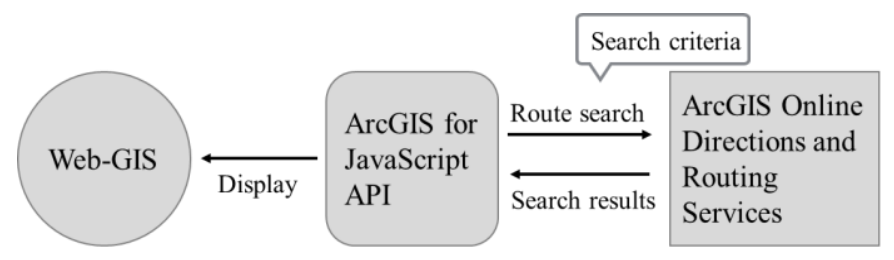

Fig. 2. Process up to the route display 


\section{3) Recommendation system}

The recommendation system has 3 methods including the collaborative recommendation, the content-based recommendation and the knowledge-based recommendation (Jannach et al., 2012) [16]. The recommendations of this study, which is based on the preference information of users concerning the sightseeing support in normal conditions, are conducted using 2 methods. The first is the knowledge-based recommendation, which recommends sightseeing spots that have features which match the tags registered as preference information by users. The reason for using the knowledgebased recommendation is to solve the cold-start problem, which is when appropriate information to recommend new users to this system is lacking. Therefore, as it was decided that knowledge-based recommendation which explicitly ask users for preference information and create profiles are necessary, the system was originally designed according to the purpose of this study.

The second is the collaborative recommendation, which supports the tour planning based on the activity history registered by users. Activity history lists sightseeing spots, which were visited in one day, in chronological order, and shows whether users were satisfied or dissatisfied with each sightseeing spot. Based on this information, a user model is created using the Support Vector Machine (SVM), the model is matched with the activity history of other users, the degree of similarity is determined, and users with similar preferences are detected. Afterwards, regarding the activity history of users with similar preferences, a pattern mining, which lists and extracts time series activities of sightseeing a group of locations, will be conducted. The pattern mining in this study will use categories. The 7 categories, which divide sightseeing spots according to each feature, used in this study include food/drinks, shops, entertainment, events, scenery, art and recreation. All sightseeing spot information belongs to one of these categories. Therefore, each sightseeing spot information in the activity history will be put in the category it belongs to, and the categories corresponding to the list of sightseeing spots visited in chronological order will be used as the new activity history. Then, the system will extract patterns of categories from the activity history of users with similar preferences, and recommend patterns with the highest relativity score as described in Section V. Regarding each category within the recommended patterns, by selecting and matching sightseeing spot information belonging to each category, a tour plan is made. In addition, concerning evacuation support, by calculating the distance based on longitude and latitude, the closest evacuation site as well as disaster support facilities within a certain distance can be recommended based on the user's current location.

\section{4) Smart glasses}

Smart glasses are a wearable terminal in the form of glasses, and have been developed by various companies in recent years. In this study, the system will be designed with the assumption that the smart glasses made by SONY will be used. The reasons why the smart glasses was selected are because the binocular lenses provide high visibility in various environments, and by using the GPS of cooperating mobile information terminals, information according to the current location of users can be provided. In addition, concerning the Osaka marathon held in Osaka City on October 2014, from the demonstration experiment where the runners ran with the smart glasses on, it is anticipated that the products have been developed with the concept that it will be used while users are moving, which is compatible with the purpose of this study where it is assumed that the system will be used while users are walking.

With the smart glasses, the navigation is conducted by providing the direction and distance from the current location to the destination by means of the location information. In addition, while the navigation system is working, real time information concerning the destination will be provided whenever necessary. The information provided is information regarding sightseeing spots obtained by SNS comments and Twitter.

\section{F. Management of submitted information}

As the standard of validity of submitted information concerning sightseeing spots are vague, it is difficult to determine whether or not the content is appropriate. However, if information submitted by users are not managed, when a user with ill intent appears, the reputation of a specific sightseeing spot may be damaged arbitrarily. If users have knowledge concerning the region of operation, the legitimacy of submitted information can be determined based on experience. However, users who do not have any knowledge will not be able to determine the legitimacy and may make incorrect evaluation concerning sightseeing spots. In this case, the information of the sightseeing spot is inappropriate, and it will affect information recommendations as recommendations suitable for users will not be possible, which will ultimately damage the value of the system. Therefore, in this study, if the manager detects any submissions with ill intent, regarding the account that created the submission with ill intent, the system is designed so that authority to delete the submission and account can be exercised. By means of this, this study aims to design a system that can operate on a long-term basis.

\section{SySTEM DEVELOPMENT}

\section{A. System frontend}

\section{1) Functions for sightseeing support in normal conditions}

\section{a) Submitting function of sightseeing spot information}

By clicking on the "spot submissions" in the menu bar, users will be moved to the submitting page of sightseeing spot information. On the submitting page of sightseeing information, users can submit sightseeing spot information by entering the name, description, images and location information of the sightseeing spot. The location information of the sightseeing spot can be entered by clicking the target location on the Web-GIS. In addition, by clicking the "display past submitted locations", users can confirm whether the same sightseeing spot information has been submitted in the past.

\section{b) Viewing function of sightseeing spot information}

Users can return to the homepage by clicking "home" in the menu bar, and view sightseeing spot information submitted by users in the past on the Web-GIS. Each sightseeing spot information is displayed with different color markers according 
to each category, and the category of each marker is explained in the image below the Web-GIS. When clicking the marker, a bubble containing the name and image of the sightseeing spot will be displayed. By clicking the bubble, users will be moved to the details page of the selected spot which will enable them to check the detailed information.

In the details page of sightseeing spots, the comment and tag functions can be used. The comment function will enable communication between users as well as supplementary information to be added to sightseeing spot information. In addition, Tweets related to sightseeing spots obtained through Twitter is also displayed in the comment section. These comments and Tweets are considered real time information of sightseeing spots. Regarding the tag function, the features of sightseeing spots can be freely added as tags by users. Users can use tags that have been registered in the past as well as tags that have been newly registered. Additionally, by clicking tags that have already been added, additional importance can be placed on the tag. The most commonly used tag will be used as the feature of the sightseeing spot when recommended. All tags belong to a category, and the category that the most-used tag of a sightseeing spot belongs to will also be the category in which the sightseeing spot belongs to. In addition, by clicking on "start navigation from your current location", users can receive navigation on the Web-GIS to any sightseeing spot from their current location.

\section{c) Registering function of activity history}

By clicking on "history" in the menu bar, users will be moved to the activity history registration page. Activity history is made up of users' evaluation of previously visited sightseeing spots, within the region of operation, in addition to the budget and group when visiting the sightseeing spots. The number of sightseeing spots that can be registered are 2 to 5 . In addition, if the activity history is already registered, the confirmation screen of activity history will appear. On the confirmation screen of activity history, by clicking the button with each activity history name, users can confirm the activity history registered in the past. The contents of activity history that will be displayed include the name, image and category of each sightseeing spot.

\section{d) Support function of tour planning}

By clicking "plans" in the menu bar, users will be moved to the tour planning page. Concerning the tour planning page, users can receive tour planning support from the system based on the registered activity history. First, concerning the tour planning, the budget and group and the number of sightseeing spots that the users would like to visit must be entered and sent as conditions. Based on the conditions and activity history of each user, the system will recommend patterns made up by categories. Regarding each category in the pattern recommended, users can select and match sightseeing spots belonging to each category and create a tour plan. In addition, in order to efficiently create a tour plan, the location information of sightseeing spots applied to each category will be actively displayed on the Web-GIS. If the tour plan is already made, users will be moved to the tour plan confirmation screen, and the name, image and category of sightseeing spots will be displayed according to the order on the sightseeing schedule. To send the displayed tour plan to the smart glasses, users must click the "setup the plan in smart glasses". By clicking the "start navigation", the navigation of the tour plan will start on the Web-GIS.

\section{e) Navigation function}

By clicking the "start navigation from current location" on the details page of sightseeing information or the "start navigation" on the confirmation screen of the tour plan, the first option will take the users to the navigation screen for single sightseeing spots, and the second will take users to the navigation screen for several sightseeing spots. Regarding navigation for single sightseeing spots, navigation will be conducted by displaying the current location and the route from the current location to the user's destination on the Web-GIS. In addition, for navigation of several sightseeing spots, the navigation will be conducted by simultaneously displaying the current location and the route for several sightseeing spots.

\section{f) Recommendation function of sightseeing spot information}

Users will be moved to the recommendations page by clicking the "recommended" in the menu bar, and sightseeing spots with the most-used tags that are also registered as the users' preference information will be recommended. The information of the recommended sightseeing spots will be listed in tile form, and the content will include the name, description, image and category of each sightseeing spot.

2) Functions for evacuation support in emergency situations in the event of disasters disasters

a) Viewing function of support facilities in the event of

Users can go to the homepage by clicking "home" in the menu bar, and view information of disaster support facilities (evacuation locations, evacuation sites, temporary accommodation, water supply points and medical institutions), published by the disaster prevention map of Yokohama city which is within the region of operation, on the Web-GIS. The information of these disaster support facilities are marked differently according to the facility on the digital map of the Web-GIS, and the type of marked facilities are explained below the image of the Web-GIS. When clicking the marker, a bubble with the name of the disaster support facility will be displayed, and for more detailed information, users can click the bubble which will take them to the details page of the selected disaster support facility. The comment function can be used on the details page of disaster support facilities. The comment function enables communication between users and the supplementation of information concerning the disaster support facilities. In addition, by clicking the "start navigation from current location", users can receive navigation from their current location to the selected disaster support facility on the Web-GIS.

b) Search function of support facilities near users in the event of disasters

Users can go to the nearby disaster support facility page by clicking the "nearby disaster support facilities" in the menu bar, and disaster support facilities that are within $1 \mathrm{~km}$ from the user's current location will be recommended. The 
recommended disaster support facilities will be listed in tile form, and the name, facility type and distance from the user's current location to the facility of each disaster support facility will be displayed.

\section{c) Navigation function to the closest evacuation sites}

By clicking the "evacuation navigation" in the menu bar, users can move to the navigation page that shows the route to the closest evacuation location from the user's current location.

\section{B. System backend}

\section{1) Information obtained through Twitter}

In this study, real time information is gathered through Twitter in addition to the originally designed SNS. Twitter API 1.1 is used to obtain Tweets from Twitter. Tweets that are obtained in normal conditions are those submitted within 24 hours that include the words "Minatomirai" or "\#Minatomirai", and have been retweeted or added to favorites 5 times each. Taking the text out of each obtained Tweet, a search of letter strings by means of regular expressions will be conducted. The searched letter string is to be the names of all sightseeing spots submitted on SNS, and if a matching letter string is found, that Tweet will be registered in the database as comment relating to the sightseeing spot matched by the letter string. In the event of disasters, Tweets including "\#DynamicNavigation" in addition to having location information will be obtained. This system obtains Tweets every minute because the Twitter API has restricted the number of Tweet obtainment to 15 times in 15 minutes.

\section{2) Calculation of the similarity ratio of preferences} between users

With the method of Fujitsuka et al. (2014) [2] as a reference, SVM will be used for the similarity rate calculations of preferences between users in this study. SVM is one of the methods of machine learning, and it can also make models that discern different patterns in order to divide data into several classes. In this study, users' activity history will be used as learning data, and budget/group and tags will be treated as features, while class will be divided into satisfactory class and dissatisfactory class. First, a user model based on the activity history of users will be made, the activity history of a different user will be applied to it, and the data will be divided into the satisfactory class or the dissatisfactory class. By comparing the aforementioned user model and the separation results, the ratio of matched satisfaction and dissatisfaction among the activity history will be set as the preference similarity rate between users. Using the study results of Fujitsuka et al. (2014)[2] as a reference, and basing the level of similarity rates discerned as being able to appropriately determine similar users by the operation tests (Section VI) mentioned later, this study will set those with a similarity rate of over $60.0 \%$ as users with similar preferences.

\section{3) Creating recommendations}

In normal conditions, in order to support the sightseeing spot recommendation based on users' preference information as well as the tour planning based on users' activity history, this system has made recommendations regarding users. Concerning the former, tags registered as user preference information and the most-used tags among the tags included in sightseeing spot information will be put together, and the matching sightseeing spot information will be recommended. Concerning the latter, calculations of the similarity rate between users will be made, and based on the activity history of users with similar preferences as well as the conditions presented from users, recommendation will be made using the pattern mining method. In particular, sightseeing spot information included in the activity history will first be converted to the category it belongs to, and the category group will be made. Then, all patterns from the category groups will be extracted. Next, as shown in Fig. 3, the closeness (degree of distance) will be solved with the chronological order of the categories in mind in contrast with the extracted patterns, the closeness score of each pattern will be calculated by multiplying the support rate of patterns (appearance ratio), and this will enable the recommendations with the highest pattern. Also, in the event of disasters, based on the current location information of users, the closest evacuation location and disaster support facilities within a certain distance from the users will be recommended.

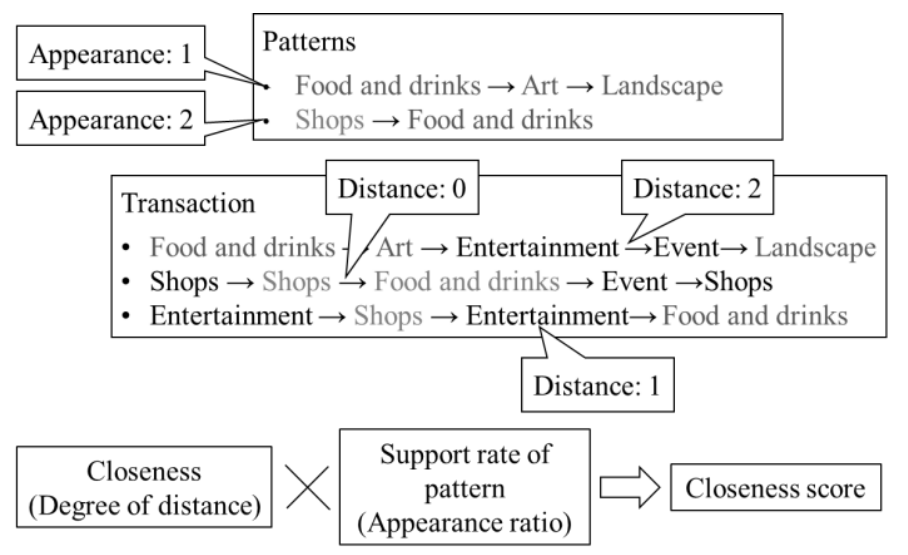

Fig. 3. Calculation method of the adjacency ratio score

\section{4) Change of route}

During navigation, by means of comments submitted on SNS and information obtainment through Twitter, routes will be changed when the system perceives higher real time information. Concerning normal conditions, when comments and Tweets concerning sightseeing spots are registered to the system, users receiving navigation will be notified about this and whether the user would like to visit the sightseeing spots. If the user would like to visit the sightseeing spot, the route will change by adding the sightseeing spot. Concerning disasters, if Tweets concerning the disaster which also include the word "DynamicNavigation" and the location information are obtained, the location information will be extracted from the Tweet, and it will be dealt as barrier information. Afterwards, by searching for new routes that arrive at the destination without going through the location shown in the extracted barrier information, the route will be changed.

\section{5) Switching to the emergency mode}

This system can be switched to emergency mode only by the manager in the event of disasters. Concerning the switch to emergency mode, the manager can either rewrite the text file within the system, or click the "switch to emergency mode" button which only appears on the home screen of the manager 
after logging in. In addition, the switch to normal mode from emergency mode can be done in the same way only by the manager.

\section{System interface}

The interface is optimized according to the user's PC screens (Fig. 4), mobile information terminal screens (Fig. 5), smart glasses screens (Fig. 6) and manager screens. The PC screen interface has the layout with a menu bar allowing easy access to each function. In addition, because it is designed to use 1 function on 1 page, users who are new to the system can easily use it. The interface for mobile information terminals is basically the same as PCs, but by changing the layout and size of items according to the size of the screen, the operability of the system is made easy. Regarding the interface for smart glasses screens, the distance and direction of the destination from the user's current location will be displayed and comments and Tweets concerning the destination will also be provided when necessary. Also, in order to maintain safety while users are walking, information will be displayed only on the bottom half of the screen. Managers can manage information saved in the database, which include personal information of users' and submitted information, on the manager screen. Information is displayed in a list form on the manager's screen, and as information is deleted using the Graphical User Interface (GUI) operation, the system is designed so that management can be possible regardless of the manager's IT literacy.

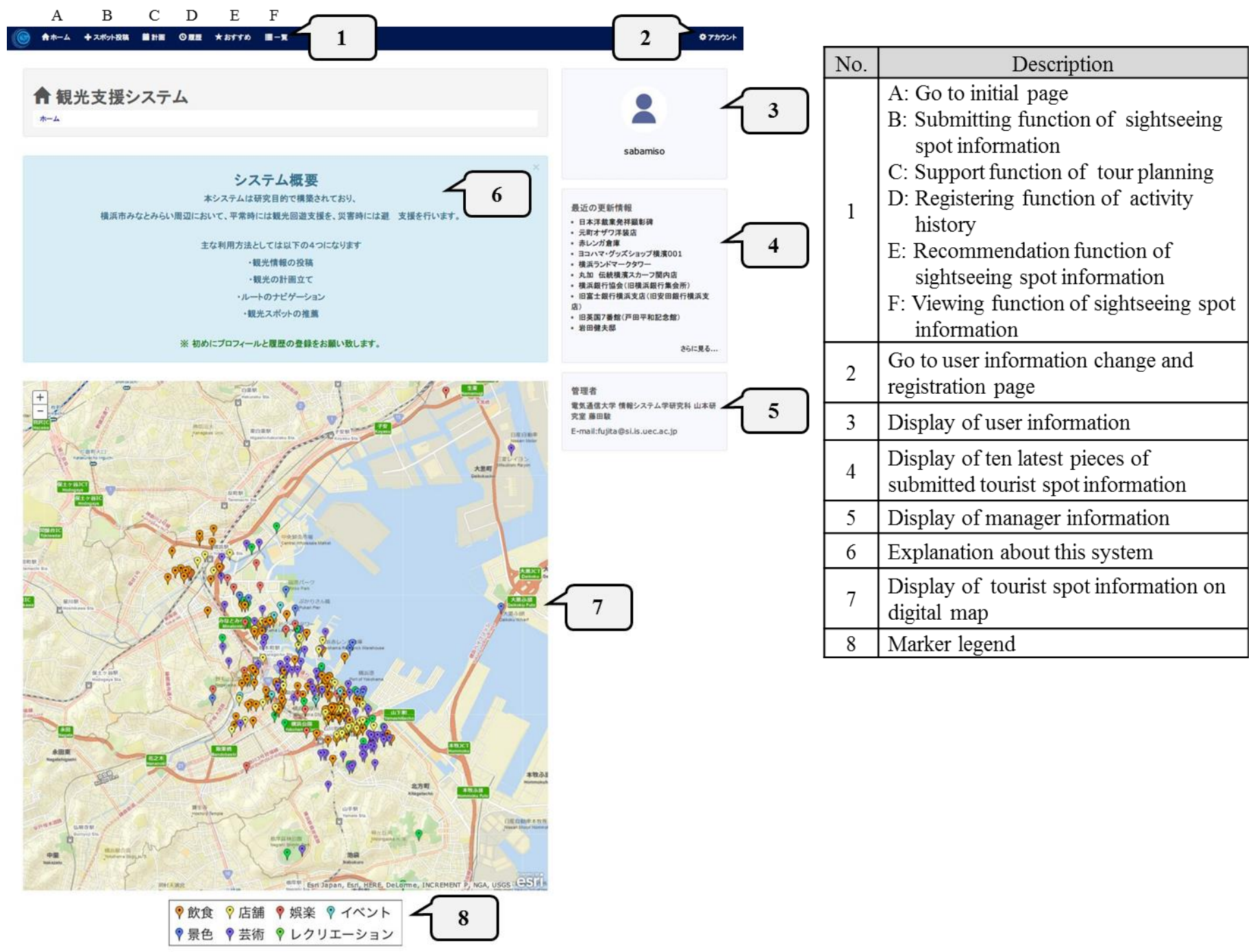

Fig. 4. Interface for PCs (Normal mode assuming normal conditions) 


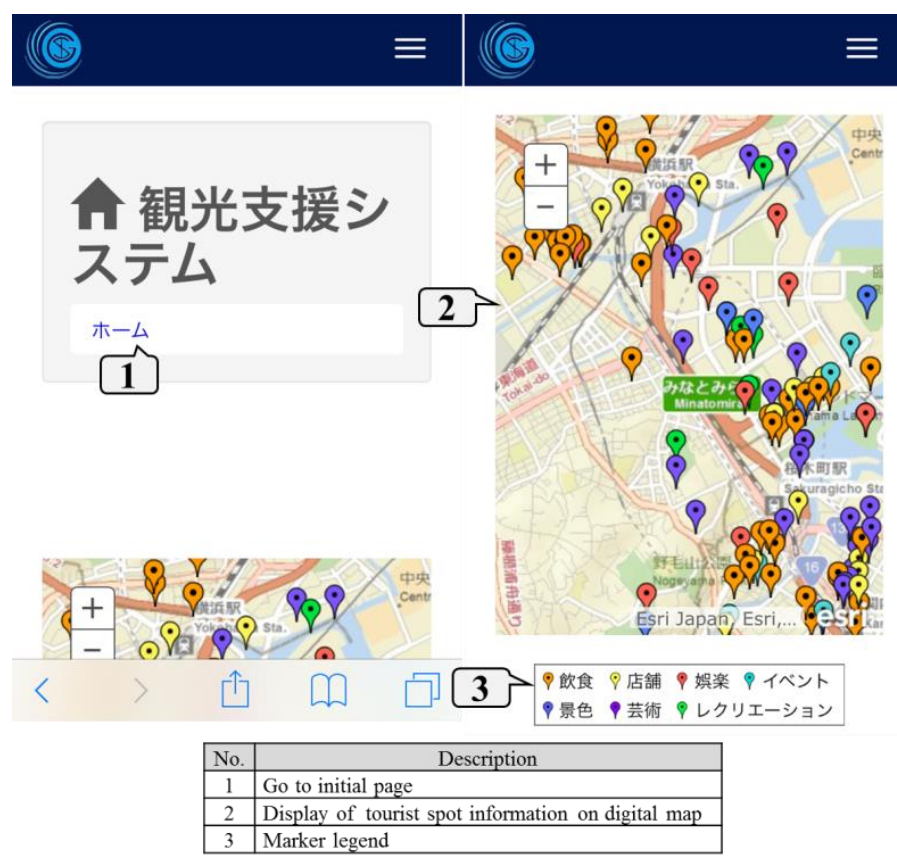

Fig. 5. Interface for mobile information terminals (Normal mode assuming normal conditions)

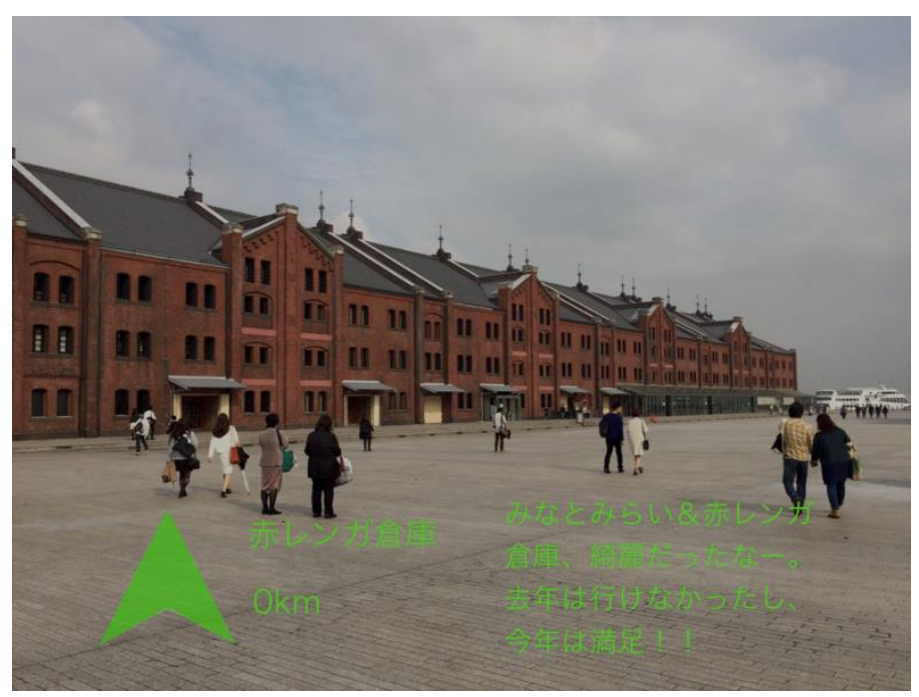

Fig. 6. Image of the interface for the smart glasses

\section{OPERATION TESTS AND OPERATION}

Following the operation process in TABLE I, the operation was conducted after the operation test and operation test evaluation of the navigation system that was designed and developed in this study.

\section{A. User assumption}

Before the operation, 6 students in their 20s were selected and a two-week operation test was conducted. From the hearing survey results of the test subjects after the operation test, three points of improvement were found in areas including the location information of tourist spots on the detailed information viewing page, the information display method on an AR Smart Eyeglass, and the updating of tourist spot information displayed on Android apps, and the system was restructured regarding these points only.

The users of the system are assumed to be those both inside and outside the region of operation. It is also assumed that users accessing the system from outside the region of operation will mainly use PCs while inside, and will use the submitting, viewing and recommending function of sightseeing spot information, the submitting function for activity history, the support function for tour planning, and the navigation function in order to confirm routes. For users accessing the system from within the region of operation, it is assumed that they will be using mobile information terminals inside and outside, and that they will mainly use the submitting and viewing function of sightseeing spot information and the navigation function in order to visit sightseeing spots, which will both use the current location information of users. In addition, regarding the submitting function of sightseeing spot information, the use method of those with knowledge concerning the region of operation and those without will be different. It is assumed that the former, in addition to submitting sightseeing spot information that they already know about, will make submissions concerning the sightseeing spot evaluation using comment and tag functions. For the latter, it is assumed that they will visit sightseeing spots based on submitted information, and make submissions concerning the evaluation in the same manner as the former.

\section{B. Operation tests and operation test evaluation}

Before the operation directly via the web using PCs and mobile information terminals, a 1-week operation test was conducted with 5 students in their 20 's, who belong to the authors' lab, as subjects. From the hearing survey results of the subjects after the operation test, one point of improvement was extracted, and the system was reconfigured regarding it only. Specifically, a breadcrumb list for each page was created to clearly show the location of users on the website. In addition, concerning the operation via smart glasses, a 1-day operation test using actually the smart glasses and the same test subjects in the region of operation was also conducted. From the hearing survey results of the subjects after the operation test, the only improvement was making the size of the letters displayed on the glass bigger.

\section{Operation directly via the web using PCs and mobile information terminals}

\section{1) Operation overview and results}

Firstly, the operation directly via the web using PCs and mobile information terminals was conducted. Whether inside or outside the region of operation, the operation of the system was advertised using the website of the authors' lab, and the tourism department of Kanagawa Prefecture and Yokohama City in addition to the Yokohama Convention and Visitors Bureau (Yokohama City Tourism Association) supported this study by distributing pamphlets and operating manuals. Users must register an account by entering their email address and password. If users use a registered account to access the system for the first time, their "nickname", "gender", "age" and "preferences" must be registered as user information. "Nicknames" do not have to be the user's real name, and by 
allowing users to enter any half-width alphanumeric, users can remain anonymous.

Users will be moved to the homepage after registering user information, and functions including the submitting, viewing and recommending of sightseeing spot information, registering activity history, as well as navigation to single sightseeing spots will be made available. When activity history is registered, the support function of tour planning will be made available. Additionally, when tour plans are created, the navigation function of multiple sightseeing spot groups will be made possible based on the tour plan. When changing registered user information, by choosing the profile from the account, users will be moved to the update page of registered information. After 7 weeks of operation in normal mode assuming normal conditions, the operation in emergency mode assuming disasters was also conducted in the same region of operation with the same users for 1 week.

TABLE II shows the details of users during the 7-week operation as mentioned above, and Fig. 7 similarly shows the transition of the total number of users. The number of users gradually increased, and the total number of users were 86 , with 40 male users and 46 female users. The percentage of users in their 20's was $67 \%$, those in their $30 \%$ was $12 \%$, those in their 40 's was $8 \%$, and the total of those in their $20 \sim 40$ 's occupied $87 \%$ of the total number of users. As shown in the 2015 Telecommunications (2015) [17], this is in harmony with the fact that the main users of general SNS are those in their 20 40's. After having each user use this system for a month, the evaluation by means of a web questionnaire survey was conducted.

\section{2) Use of submitted information and the comment and tag} functions

Fig. 7 also shows the transition of the number of submissions during the 7-week operation as mentioned above, and the significant increase in submissions from the 4th week was clear. This may because users who gradually got used to the system started submitting information they knew or thought was necessary halfway through the operation period. In addition, in order to solve the cold-start problem mentioned in Section IV, the 181 items of sightseeing spot information gathered by Ikeda et al. (2014) [15] was prepared as initial data. As the total number of submissions during the operation period was 170, a total of 351 sightseeing spot information items were accumulated in this system.

TABLE I. OPERATION PRocess OF THE SyStem

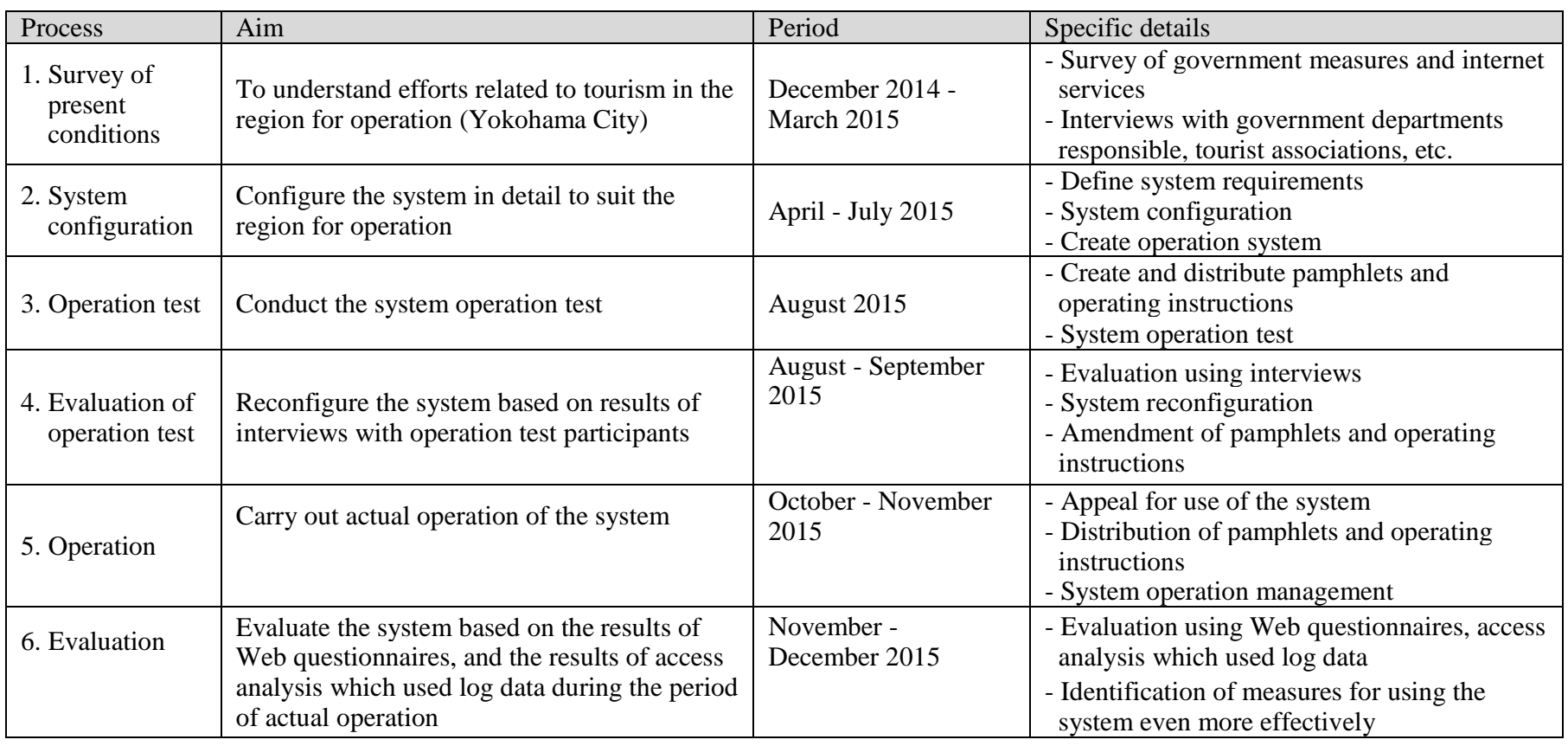

TABLE II. OutLine OF USERS AND RESPONDENTS to the Web QuestionNAIRE (OPERATION DiReCtLy Via THE Web USING PCS AND MobILE INFORMATION TERMINALS)

\begin{tabular}{|l|l|l|l|l|l|l|l|}
\hline & $\begin{array}{l}\text { Aged 10 to } \\
19\end{array}$ & Twenties & Thirties & Forties & Fifties & $\begin{array}{l}\text { Sixties and } \\
\text { above }\end{array}$ & Total \\
\hline Number of users (people) & 4 & 59 & 7 & 10 & 2 & 4 \\
\hline $\begin{array}{l}\text { Number of Web questionnaire respondents } \\
\text { (people) }\end{array}$ & 3 & 37 & 2 & 6 & 1 & 86 \\
\hline Valid response rate (\%) & 75.0 & 62.7 & 28.6 & 60.0 & 50.0 & 51 \\
\hline
\end{tabular}




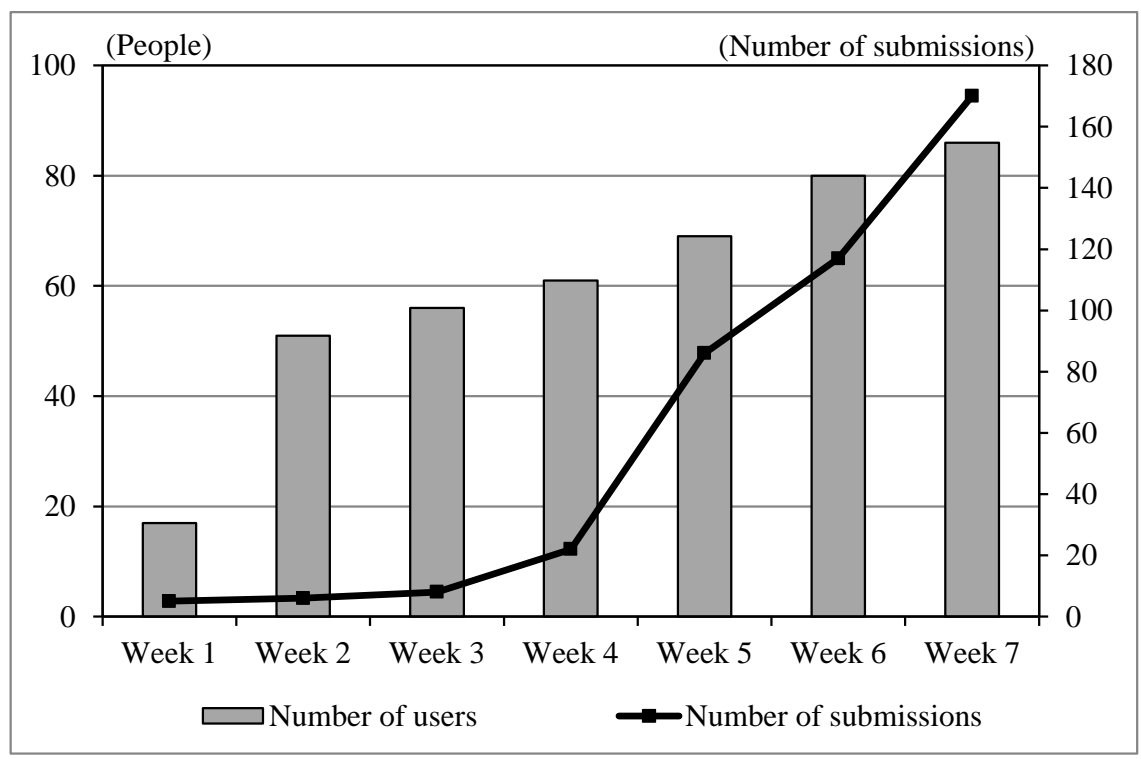

Fig. 7. Changes in the number of users and number of submissions during the operation period (operation directly via the web using PCs and mobile information terminals)

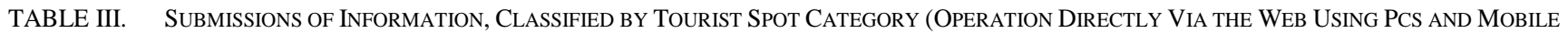
INFORMATION TERMINALS)

\begin{tabular}{|c|c|c|c|c|c|c|}
\hline \multirow{2}{*}{ Category } & \multicolumn{2}{|c|}{ All submissions } & \multicolumn{2}{|c|}{ Submission during operation } & \multicolumn{2}{|c|}{ Initial data } \\
\hline & Number & Percentage $(\%)$ & Number & Percentage $(\%)$ & Number & Percentage $(\%)$ \\
\hline Food and drinks & 126 & 35.9 & 78 & 45.9 & 48 & 26.5 \\
\hline Shops & 62 & 17.7 & 36 & 21.2 & 26 & 14.4 \\
\hline Entertainment & 25 & 7.1 & 21 & 12.4 & 4 & 2.7 \\
\hline Event & 9 & 2.6 & 5 & 2.3 & 4 & 2.7 \\
\hline Landscape & 19 & 5.4 & 4 & 2.4 & 15 & 7.3 \\
\hline Recreation & 26 & 7.4 & 5 & 3.5 & 21 & 11.6 \\
\hline Total & 351 & 100.0 & 170 & 100.0 & 181 & 100.0 \\
\hline
\end{tabular}

TABLE IV. OUtLINE OF USERS AND RESPONDENTS TO THE WEB QUESTIONNAIRE (OPERATION Via THE SMART GLASSES)

\begin{tabular}{|c|c|c|c|c|c|c|c|}
\hline & $\begin{array}{l}\text { Aged } 10 \text { to } \\
19\end{array}$ & Twenties & Thirties & Forties & Fifties & $\begin{array}{l}\text { Sixties and } \\
\text { above }\end{array}$ & Total \\
\hline Number of users (people) & 4 & 10 & 3 & 8 & 7 & 2 & 34 \\
\hline
\end{tabular}

TABLE III shows submitted information concerning sightseeing spots by category. As shown in TABLE III, during the operation period, although many submissions were of categories including food and drinks (78 items, 46\%) and shops (36 items, 21\%), information concerning all categories were submitted. Additionally, with almost all submitted information, related images were also submitted. From these results, it can be said that various sightseeing spot information is submitted and information attached with images for the recommendation of sightseeing spots according to the preference of each user is accumulated in line with the purpose of this system.

11 comments were made and 111 tags were registered to sightseeing spot information by users during the operation period. Although the comment function is not used often, from the fact that evaluation using the tag functions was made often, it is understood that communication between users is made mainly through the tag functions. This may because the tag function is easier to use as users only need click on a tag to give the submission more weight, while the comment function requires users to enter sentences.

\section{Operation via smart glasses}

Between Yamashita Park and the Yokohama Red Brick Warehouse located within the region of operation, on December 11th and 18th, 2015, the operation via the smart glasses was conducted with tourists as subjects. Users put the smart glasses on and received navigation for $600 \mathrm{~m}$ between the above-mentioned two places. The reason why such a route was chosen is because there are no cars which enables users to receive navigation safely. Additionally, in consideration for the safety of users, an escort was assigned to all users.

TABLE IV shows the details of users during the 2 days of the operation period as mentioned above, and the total number of users was 34, with 18 male users and 16 female users. When divided according to age, although those in their 20's were the 
most numerous occupying $29 \%$ of the total number of users, the age of users were scattered, and no one had experience using the smart glasses. Just after the operation, all users were required to answer the web questionnaire survey.

\section{EVALUATION}

In this section, based on the questionnaire survey results as shown in the overview in TABLEs II and IV, the evaluation concerning the system using the web system and the smart glasses is conducted. Next, based on the access analysis results using the log data from during the operation, the evaluation concerning the activity support during both normal conditions and disasters is conducted. In addition, based on these evaluation results, points of improvement for this system are extracted.

\section{A. Evaluation based on the questionnaire survey results concerning the operation directly via the web using PCs and mobile information terminals}

\section{1) Evaluation concerning the use of the system}

Fig. 8 shows the evaluation results concerning the use of this system in normal conditions and disasters. Regarding the usefulness in tourist spots in normal conditions, all answered were either "I agree" and "I somewhat agree", and $74 \%$ answered "I agree" which is a significantly high number. When switching from normal mode assuming normal conditions to emergency mode assuming disasters, although a high number of $88 \%$ answered "I agree" or "I somewhat agree" concerning the smooth use, $12 \%$ answered "I somewhat disagree" or "I completely disagree". Because the functions of this system used in the event of disasters completely differ from those used in normal conditions. However, concerning the usefulness in the event of disasters in tourist spots, with all answers being either "I agree" and "I somewhat agree", a significantly high percentage of $69 \%$ answered "I agree". From the information above, regarding the support of both sightseeing in normal conditions and the evacuation in the event of disasters, it can be said that this system is effective.
Also, concerning whether users would like to use this system in the future, as $96 \%$ answered "I agree" or "I somewhat agree", the continuation of this system's operation in the future can be expected.

\section{2) Evaluation concerning the function of the system}

a) Evaluation of use frequency according to the function

Fig. 9 shows the evaluation results concerning the frequency of use according to the function while in normal mode assuming normal conditions, and also shows the aforementioned according to the type of information terminal mainly used and those used in this entire system. In particular, the ratio of those who chose the top 2 frequently used functions will be shown according to the function. This entire system has a high percentage of $53 \%$ in the "viewing function of sightseeing spot information" followed by the "recommendation function of sightseeing spot information" with $45 \%$, and this shows that the system's main purpose of use is the gathering of sightseeing spot information. In addition, regarding the use tendency of each function according to the type of information terminal, the results for PCs were the "viewing function of sightseeing spot information (53\%)", the "recommendation function of sightseeing spot information $(50 \%)$ " and the "support function of tour planning (39\%)". For mobile information terminals, although the percentage of the "viewing function of sightseeing spot information (53\%)" is the same as that of PCs, it is followed by the "navigation function (40\%)", the "recommendation function of sightseeing spot information (33\%)" and the "support function of tour planning (33\%)". Excluding the basic function related to the submitting and viewing of sightseeing spot information, as the support of tour planning and the recommendation function of sightseeing spot information for PCs used indoors, and the navigation function for mobile information terminals used indoors and outdoors are designed to be the main functions of this system, the results mentioned above show that this system is used as planned when the system was being designed (see Section IV).

Usefulness in tourist spots in normal conditions

Switching from normal mode assuming normal conditions to emergency mode assuming disasters

Usefulness in the event of disasters in tourist spots

Whether users would like to use this system in the future

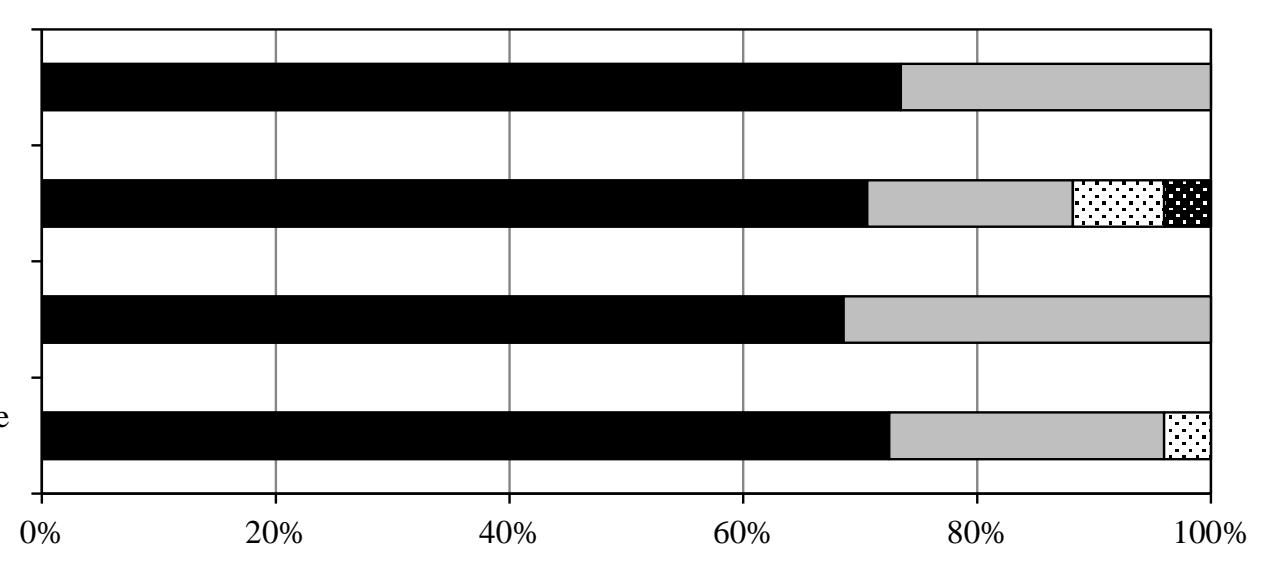

I agree

$\square$ I somewhat agree

๑I somewhat disagree

I disagree

Fig. 8. Evaluation results concerning the system use 


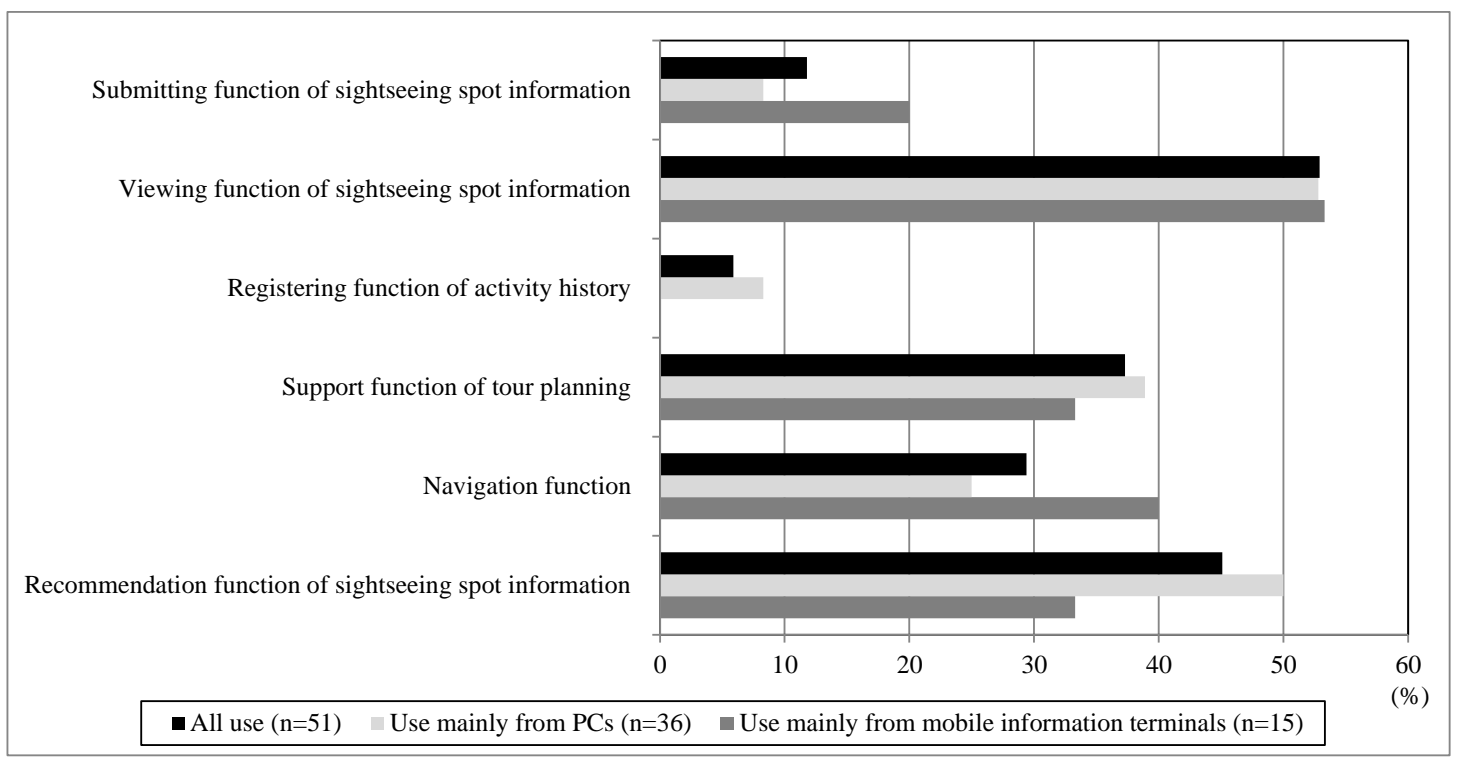

Fig. 9. Evaluation results concerning the use frequency according to the function while in normal mode assuming normal conditions

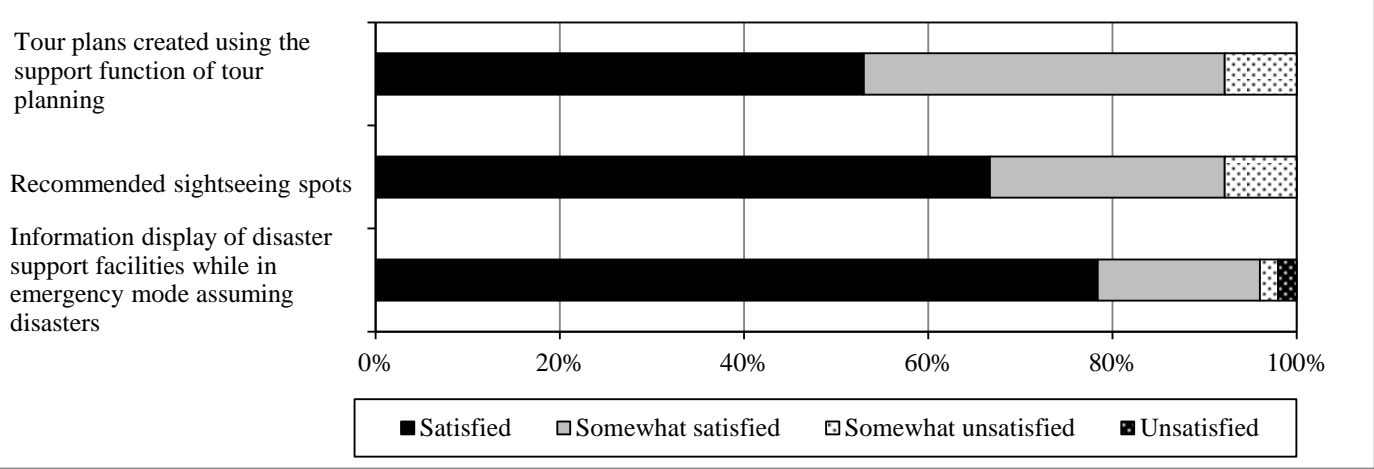

Fig. 10. Evaluation results concerning the satisfaction level of the original features

b) Evaluation concerning the satisfaction rate of the original function of this system

Fig. 10 shows the evaluation results only of the results provided to users, among the original functions of this system, in which the satisfaction rate can be questioned (the support function of tour planning and the recommendation function of sightseeing spot information used while in normal mode assuming normal conditions, in addition to the information display function of disaster support facilities while in emergency mode assuming disasters). Concerning the tour plans created using the support function of tour planning and the recommended sightseeing spots, $93 \%$ answered "satisfied" or "somewhat satisfied" for both, and the result of the latter was especially good with $67 \%$ answering "satisfied". From these results, it can be said that the recommendation system integrated into this system has provided appropriate sightseeing spot information for users. Additionally, regarding information display of disaster support facilities while in emergency mode assuming disasters also, as $96 \%$ answered "satisfied" or "somewhat satisfied", it can be assumed that this system can provide users with disaster support facility information appropriately in the event of disasters.
B. Evaluation based on the questionnaire survey results of the operation via smart glasses

1) Evaluation concerning the use of the system

Fig. 11 shows the evaluation results concerning the system using the smart glasses. $94 \%$ answered "easy" or "relatively easy" regarding the usability of the smart glasses, and from the fact that all users had no experience using the smart glasses previously, it can be said that the use of the smart glasses concerning this system is easy even for users who have never used it before. Concerning the suitability of smart glasses in comparison to smartphones while sightseeing, in addition to the suitability of navigation by means of the smart glasses, 91\% answered "suitable" or "relatively suitable" for both situations. The former had especially high results as $74 \%$ answered "suitable". The reason for this is that, in addition to the usability of the smart glasses as mentioned above, as the smart glasses, unlike mobile information terminals, can display information right in front of users, users can take in information while looking ahead instead of looking down. Therefore, in order to realize efficient and safe navigation which is the aim of this study, it is beneficial to use the smart glasses for this system instead of only using mobile information terminals. 
2) Evaluation concerning the safety of the smart glasses

Fig. 12 shows the evaluation results concerning the safety of the smart glasses. Regarding whether the information display on the smart glasses obstructs the view of users, although 79\% answered "Not obstructed" or "Not obstructed greatly", the other $21 \%$ answered "somewhat obstructed". On the other hand, regarding whether users felt any danger while walking with the smart glasses on, $91 \%$ answered they "did not feel any danger" or "did not feel any great danger". From these results, it can be assumed that although the users' view was somewhat obstructed by the navigation information displayed on the bottom half of the screen, it did not obstruct the view in a way that would make users' feel endangered. Therefore, concerning this system, it can be said that safe navigation using the smart glasses was realized.

\section{Evaluation concerning the activity support for users}

1) Overview of access analysis

In this study, by conducting an access analysis using log data gathered during the operation directly via the web using PCs and mobile information terminals, the evaluation focusing on the number of times accessed as well as the access method will be made. This study will incorporate the API of Google Analytics to the developed program, and then the access analysis will be conducted. Google Analytics is a web access analysis service provided by Google, and it can obtain access information of users concerning the website. In order to use Google Analytics, concerning the website used in the access analysis, a tracking code must be added directly to the HTML of each page.

\section{2) Evaluation based on the access analysis results}

First, the access log analysis of users concerning operation while in normal mode assuming normal conditions was conducted. The total number of sessions was 358, and concerning the information used as the method for accessing this system, PCs were $77 \%$ and mobile information terminals were $23 \%$. TABLE V shows the number of times each function was accessed, and the most accessed was the "viewing function of sightseeing spot information (27\%), " followed by the "support function of tour planning (20\%)" and the "register function of activity history (19\%)". From these results, it can be said that PCs are used as the main access method for those outside the region of operation, and that the gathering of information and tour planning are the main purpose of use. This is in line with the assumption of users' use method outside the region of operation, as mentioned in Section VI.

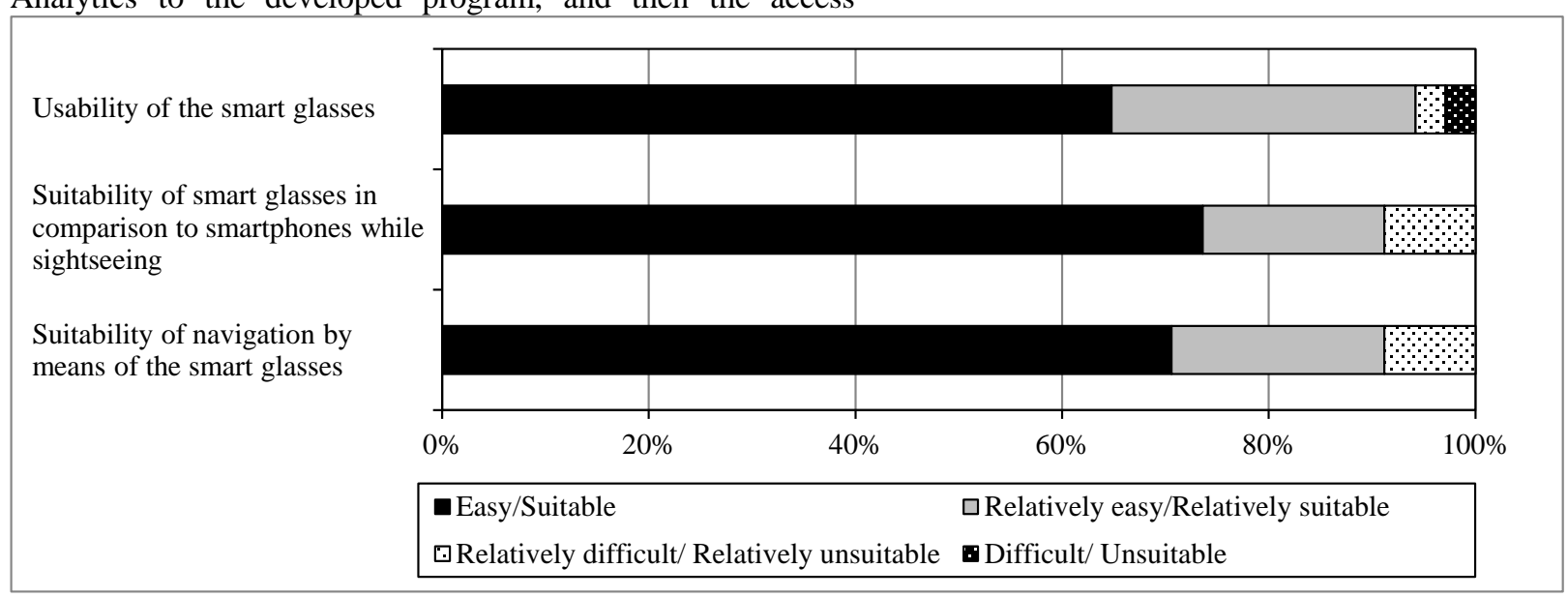

Fig. 11. Evaluation results concerning the use of the system using smart glasses

Whether the information display on the smart glasses obstructs the view of users

Whether users felt any danger while walking with the smart glasses on

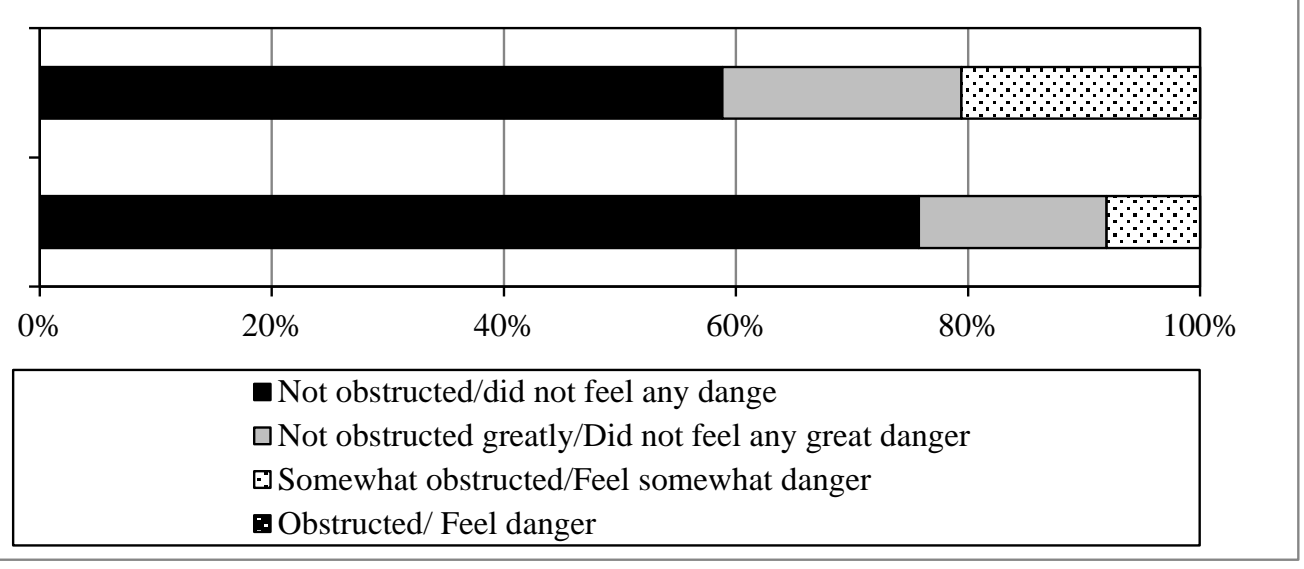

Fig. 12. Evaluation results concerning the safety of the smart glasses 
TABLE V. TOP 10 OF THE MOST Visited PAGES ACCORDING TO THE TYPE OF INFORMATION TERMINALS

\begin{tabular}{|l|l|}
\hline $\begin{array}{l}\text { Functions for normal mode assuming normal } \\
\text { conditions }\end{array}$ & $\begin{array}{l}\text { Total number of } \\
\text { accesses (556) }\end{array}$ \\
\hline Submitting function of sightseeing spot information & 13.8 \\
\hline Viewing function of sightseeing spot information & 27.0 \\
\hline Registering function of activity history & 18.9 \\
\hline Support function of tour planning & 19.6 \\
\hline Navigation function & 7.3 \\
\hline $\begin{array}{l}\text { Recommendation function of sightseeing spot } \\
\text { information }\end{array}$ & 13.4 \\
\hline Functions in emergency mode assuming disasters & $\begin{array}{l}\text { Total number of } \\
\text { accesses (116) }\end{array}$ \\
\hline $\begin{array}{l}\text { Viewing function of support facilities in the event of } \\
\text { disasters }\end{array}$ & 44.5 \\
\hline $\begin{array}{l}\text { Search function of support facilities near users in the } \\
\text { event of disasters }\end{array}$ & 22.2 \\
\hline Navigation function to the closest evacuation sites & 33.3 \\
\hline
\end{tabular}

Next, the access log analysis of users concerning the operation while in emergency mode assuming disasters was conducted. The total number of sessions during the 1-week operation period was 28 , and concerning the information terminals used as a method of access to this system, the ratio of PCs and mobile information terminals were 5:5. From the increase in percentage of mobile information terminals in comparison to normal conditions, it can be said that the tendency for this system's users to use mobile information terminals became stronger when disasters are assumed. The reason for this could be that users, assuming disasters in tourist areas, thought to use this system mainly by means of mobile information terminals. Concerning the number of times each function was accessed, although the "viewing function of disaster support facilities" was accessed by almost half with $45 \%$, as functions using location information including the "search of disaster support facilities near users" and the "navigation function to the closest evacuation site" are $22 \%$ and $33 \%$, it can be said that functions requiring location information were also used actively.

\section{Extracting solutions}

From the evaluation results in this section, the two points of improvement for this system can be summarized as shown below.

(1) Implementation of the automatic switch function to emergency mode

By obtaining information of the disasters in the region of operation and reflecting this in the system, the automatic switch from normal mode to emergency mode can be made possible. This will not only lighten the load of the system manager, but will enable the switch to emergency mode and support the evacuation of users, regardless of the manager's situation in the event of disasters. However, considering the fact that the system may be switched to emergency mode because of incorrect information, the implementation of a function that allows the manager to manually switch it back is also necessary.
(2) Color classification of displayed routes concerning navigation

When navigating multiple sightseeing spots on the WebGIS, by color-coding each displayed route between sightseeing spots, the discernment of routes are made easier. This enables the operability of the navigation function to improve, and a more efficient sightseeing support is also made possible.

\section{CONCLUSION}

The conclusion of this study can be summarized into three points as shown below.

(1) In order to support sightseeing in normal conditions and evacuation in the event of disasters by integrating SNS, Twitter, Web-GIS, the recommendation system and the smart glasses, as well as gathering high real time information concerning urban sightseeing spots, a navigation system that can actively change routes was designed and developed. By means of this, concerning both normal conditions and disasters, the accumulating, sharing, recommending of information in addition to navigating users to their destination were made possible. In addition, the center part of Yokohama City in Kanagawa Prefecture was chosen as the region of operation, and details of the system were organized after conducting a survey of the current situation.

(2) Because the operation directly via the web using PCs and mobile information terminals was conducted over a period of 8 weeks, a 1-week operation test was conducted beforehand, and the system was reconfigured based on the extracted points of improvement. It was assumed that all users were over 18 regardless of whether they were located inside or outside the region of operation, and among the 86 users, a total of $87 \%$ were in their 20-40's, and the total number of submitted information was 170 . Additionally, the operation via smart glasses was conducted over the course of 2 days, and concerning the 34 users who participated, many were from different age groups and all users had no experience using the smart glasses.

(3) From the results of the Web questionnaire survey to users after the operation, it was clear that this system can appropriately support both sightseeing in normal conditions as well as evacuation in the event of disasters, and the safe and efficient navigation using the smart glasses has been realized. In addition, from the results of the access analysis using the log data form during the operation, it was shown that users, especially those outside of the region of operation used this system as assumed in normal conditions. During the operation assuming disasters, it was also shown that the tendency for users to use mobile information terminals to access this system was stronger and functions which require location information as well as the viewing function of information were actively used.

For future research issues, the new implementation of functions that support sightseeing in a more efficient way as suggested in Section VII, the increase in achievements by operating this system in other urban sightseeing spots, and the improvement in the significance of use can be raised. 


\section{ACKNOWLEDGMENT}

In the operation of the dynamic real-time navigation system and the web questionnaires of this study, enormous cooperation was received from those mainly in the Kanto region such as Kanagawa Prefecture and Tokyo Metropolis. We would like to take this opportunity to gratefully acknowledge them.

\section{REFERENCES}

[1] Y. Kurata, "Introducing a hot-start mechanism to a Web-based tour planner CT-Planner and Increasing its coverage areas", Papers and Proceedings of the Geographic Information Systems Association of Japan, Vol.21, CD-ROM, 2012.

[2] J. Sasaki, T. Uetake, M. Horikawa and M. Sugawara, "Development of personal sightseeing support system during long-term stay", Proceedings of 75th National Convention of IPSJ, pp.727-728, 2013.

[3] T. Fujitsuka, T. Harada, H. Sato and K. Takadama, "Recommendation system for sightseeing plan using pattern mining to evaluate time series action", Proceedings of the Annual Conference on Society of Instrument and Control Enginnering 2014, SS12-10, pp.802-807, 2014.

[4] T. Ueda, R. Ooka, K. Kumano, H. Tarumi, T. Hayashi and M. Yaegashi, "Sightseeing support system to support generation / sharing of sightseeing information", The Special Interest Group Technical Reports of IPSJ: Information system and Social environment (IS), 2015-IS131(4), pp.1-7, 2015.

[5] J. M. Noguera, M. J. Barranco, R. J. Segura, and L. Martinez, "A mobile 3D-GIS hybrid recommender system for tourism", Information Sciences, Vol.215, pp.37-52, 2012.

[6] M. Ye, P. Yin, W. C. Lee and D. L. Lee, "Exploiting geographical influence for collaborative point-of-interest recommendation, Proceedings of the 34th international ACM SIGIR conference on Research and Development in Information Retrieval, pp. 325-334, 2011.

[7] Q. Yuan, G. Cong, Z. Ma, A. Sun and N. M. Thalmann, "Time-aware point-of-interest recommendation, Proceedings of the 36th International
ACM SIGIR Conference on Research and Development in Information Retrieval, pp.363-372, 2013.

[8] M. Chen, F. Li, G. Yu and D. Yang, "Extreme learning machine based point-of-interest recommendation in location-based social networks, Proceedings of ELM-2015, Vol. 2, pp. 249-261, 2016.

[9] T. Yanagisawa and K. Yamamoto, "Study on information sharing GIS to accumulate local knowledge in local communities", Theory and Applications of GIS, Vol.20, No.1, pp.61-70, 2012.

[10] H. Nakahara, T. Yanagisawa and K. Yamamoto, "Study on a Web-GIS to support the communication of regional knowledge in regional communities: Focusing on regional residents' experiential knowledge", Socio-Informatics, Vol.1, No.2, pp.77-92, 2012.

[11] S. Yamada and K. Yamamoto, "Development of Social Media GIS for information exchange between regions", International Journal of Advanced Computer Science and Applications, Vol.4, No.8, pp.62-73, 2013.

[12] T. Okuma and K. Yamamoto, "Study on a Social Media GIS to accumulate urban Disaster Information: Accumulation of Disaster Information during normal times for disaster reduction measures", Socio-Informatics, Vol.2, No.2, pp.49-65, 2013.

[13] T. Murakoshi and K. Yamamoto, "Study on a Social Media GIS to support the utilization of disaster information : For disaster reduction measures from normal times to disaster outbreak times", SocioInformatics, Vol.3, No.1, pp.17-30, 2014.

[14] K. Yamamoto and S. Fujita, "Development of Social Media GIS to support information utilization from normal times to disaster outbreak times", International Journal of Advanced Computer Science and Applications, Vol.6, No.9, pp.1-14, 2015.

[15] T. Ikeda and K. Yamamoto, "Development of Social Recommendation GIS for tourist spots", International Journal of Advanced Computer Science and Applications, Vol.5, No.12, pp.8-21, 2014.

[16] D. Jannach, M. Zanker, A. Felfernig and G. Friedrich, "Recommender systems: An introduction", Cambridge University Press, U.K., 2011.

[17] Ministry of Internal Affairs and Communications of Japan, "2015 White paper -Information and communications in Japan", Tokyo, 2015. 